\title{
ANTICIPATED ETHICAL CHALLENGES WITH GROWING MOLECULAR PRENATAL DIAGNOSIS IN NIGERIA
}

\author{
Tahir, M. I. ${ }^{1}$, Ahmad, A. E. ${ }^{2}$ and Suleiman, A. B ${ }^{3}$. \\ ${ }^{1}$ Department of Medical Microbiology, Kaduna State University, Kaduna, Nigeria. \\ ${ }^{2}$ Immunology Unit, Department of Medicine, Ahmadu Bello University, Zaria, Nigeria \\ ${ }^{3}$ Department of Microbiology, Ahmadu Bello University, Zaria, Nigeria \\ Corresponding Author: sulybabs1@gmail.com
}

\begin{abstract}
Prenatal diagnostic testing is gaining more anticipated acceptance in Nigeria as more expectant mothers are offered tests to detect presence or absence of monogenetic disorders associated with foetus such as sickle cell disease. It is however known that many ethical quandaries are related to the process. These issues comprise the counselling skills, type and method of sample collection, justification for the tests requested, option of selected abortion of affected foetus and violation of other ethical principles. Ethical standards in medical laboratories are derived from medical ethics therefore, the four fundamental principles are important in managing genetic testing processes. The principles are autonomy, beneficence, non-maleficence and justice. These ethical issues are discussed in this paper vis-à-vis the foetus, the pregnant woman, society, counselling and informed consent.

Keywords: Counselling, Diagnosis, Ethics, Molecular, Prenatal
\end{abstract}

\section{INTRODUCTION}

Philosophy often oppose to empiricism as people continually remain conservative to their norms, culture and religion. The definition or scope of ethics may vary from one community to another depending on their conception about what is right or wrong. Many ethical issues in genomic research and testing in Africa express sensitivities and raise questions by communities created by their past experiences, regional cultural beliefs and practices. "Biomedical ethics (or bioethics) is an interdisciplinary field for the systematic study of ethical issues that arise in research, medicine and society. These issues can be identified within four large areas; (i) research and its application to all forms of life, from bacteria and viruses to plants, animals, and humans; (ii) allocation and delivery of health care resources; (iii) ethical problems that arise in clinical encounters between health care professionals and patients, and; (iv) ethical problems in preventive medicine and public health"(Wertz et al., 2003). Ethical standards in medical laboratories are derived from medical ethics therefore, the four fundamental principles are important in decision-making in molecular laboratory. The principles are autonomy, beneficence, nonmaleficence and justice(WHO, 1999). Bioethics as a modern study is derived from other disciplines like philosophy, theology, medicine and law (Satesh and Ahuja,1997).

The world of molecular biology is extending to embracing different facets of human endeavour such as medicine and agriculture. In medicine, the discipline has more role to play in diagnostics and genetic manipulation. The diagnostics uses techniques as regard to disease detection and quantification, pre-symptomatic or genealogy and prenatal testing.

"Prenatal diagnosis is carried out only to give parents and physicians information about the health of the fetus. The use of prenatal diagnosis for paternity testing, except in cases of rape or incest, or for gender selection, apart from sex-linked disorders, is not acceptable" (WHO, 1998). Prenatal diagnosis is used to detect foetal condition such astrisomy, sickle cell disease, cystic fibrosis and other monogenetic disorders by application of genetic testing (Jong et al., 2010). Techniques for the sample collection ranges from invasive amniocentesis and chorionic villus sampling to non-invasive prenatal diagnosis through use of foetal blood in the mother's circulation (Gates, 1993). Non-invasive prenatal diagnosis (NIPD) has come to stay since the discovery of cellfree fetal DNA/RNA (ccfDNA/RNA) in maternal circulation. This foetal genome can be obtained as early as 7 weeks during gestation (Wertz et al., 2003).

Prenatal diagnosis for sickle cell disease informs the expectant couple about the haemoglobin genotype of the unborn child. This will give them option to terminate affected foetus or prepare them psychologically, financially and medically to raise the child when abortion is not an option (Fadare, 2009). 
Prenatal diagnosis rises a number of ethical issues that include informed consent, genuine indication, risk, privacy, confidentiality and follow up treatment. Most of the ethical questions are not directed to the molecular techniques but to the outcome of the testing result. This review is expected to explore ethical issues as they relate to the foetus, mother, the society and genetic counselling and informed consent.

\section{Foetus}

Foetus is considered as a patient in its own right by some observers considering the increase in many diagnostic and therapeutic approaches targeted at improving its health being. Therefore, healthcare providers owes the foetus a duty of beneficence despite it lives within the body of a pregnant woman (Gates, 1993). While the foetus enjoy the beneficence of the obstetrician it is not seen as autonomous being in the same sense as the pregnant woman (Gates, 1993). Autonomy is the moral right to choose and follow one's own plan of life and action. Predictive genetic testing of late-onset diseases is close to violation of the minors' autonomy and privacy and should be avoided except if there is available medical intervention to alter the progress of the disease (Jong et al., 2010).

Ethical issues in prenatal testing surfaced when the aim is diverted from calming anxiety in carrier parents or preparing them to rise an affected child. Often affected foetus is aborted therefore, the testing is not instituted for the benefit of the foetus. The expected child will only benefit in few situations such as when treatment can be given or special caution or procedure is to be observed during delivery. The rapid expansion of prenatal diagnosis will disturb one balance between believing the real aim of the technology of dousing anxiety or preparing parents to nurse affected child and believing if the technology is subtly aimed at selective abortion.

Significant loss of unaffected foetus may occur during sample collection as invasive procedure of chorionic villus sampling and amniocentesis are associated with a $1 \%$ and $3.2 \%$ risk of miscarriage respectively(Wertz et al., 2003; Edwin et al., 2011). Edwin et al. (2011) stated that: "By undergoing CVS for PND, a woman accepts a one in thirty chance of miscarrying what is probably a normal foetus". Because of the non-invasiveness of the NIPD there is growing concern that selective abortion of foetuses with minor abnormalities, nonpreferred sex or unwanted paternity will become normalized (Jong et al., 2010). Selective abortion is where the parents terminate a desired pregnancy because of a congenital disorder or some other undesirable foetal characteristic (Edwin et al., 2011).

Large through-put DNA sequencing and microarray technology have contributed in understanding genes and corresponding traits. These technologies are feared will be used for eugenics (Henn, 2000). The mother when seen as the patient may have a right to whatever service she can pay for as a fulfilment of patient autonomy and justice however, PND with respect to paternity and sex testing will result to illegally aborting normal foetus. Testing of other non-disease traits may lead to illegal abortion and promote eugenics in humans (Henn, 2000).

\section{Pregnant Woman}

Potential mothers may prefer an early diagnosis to reduce psychological effect of abortion but this is coupled with increased risk of aborting genetically normal foetus. The psychological burden of selective abortion is relatively low in early gestation. Some ethicists consider foetus to have same moral status as all existing human beings while abortion protagonists opined that the moral value of foetus only increase with gestational period (Edwin et al., 2011). Whatever is the moral status attached to the foetus, the expectant mother will have psychological impact when abortion is chosen as an option for affected foetus.

\section{Society}

Nigerian law has explicitly considered abortion illegal and carries a heavy jail sentence up to 14 years imprisonment unless it is performed to save the life of the pregnant woman. "Every law, to be competent, as to regulate human and socio-political affairs ought to be reasonable and for law to be reasonable, it must draw from the rich deposits of moral, religious and sociological considerations which blend into the normative composite of the richest values of human history" (Maurice, 2011). The existing law has not permitted abortion for foetal deformity. The law is for ethical protection and defence of the human life from womb to tomb (Maurice, 2011).

Society often influences mothers' autonomy as consenting to undergo PND is considered an indication of responsible parenting. Less sympathy might be shown if PND is forgone and a child is born with diagnosable abnormality (Gates, 1993). 
Prenatal diagnosis and subsequent selective abortion of affected foetus have lessen motivation in addressing some research questions on cure for genetic disorders (Edwin et al., 2011).

Persons living with genetic disorders or disabilities often bewail that undergoing PND with preconceived aim of aborting affected child is a sheer discrimination against them and an indication that their lives are worthless. History has recorded many affected individuals that contributed immensely to the society than the many without such disorders. Some wonder why the society will promote many campaigns to uphold animal rights and conservation but abort its babies because of genetic disorders. Health insurance firms may tend to sway mothers' decision on fate of affected foetus to avoid repeatedly shouldering financial burden of a sick child (Gates, 1993).

\section{Counselling and informed consent}

Prenatal diagnosis was introduced on the ground that genetic counselling will remove anxiety of mothers, reduces the number of children born with genetic disorders and improve economic gain to the society (Edwin et al., 2011). Counselling is important in enhancing decision making through pre-test counselling which should give truthful information about the test and the possible associated risks. Medical and social implications of the test are expected to be discussed (Gates, 1993).

One of the challenges faced in PND is infringement of patients' autonomy when the counselling session tends to be coercive. The pre-test counselling is not always non-directive and may not be unconnected with counsellor that refer genetic testing to tests vendors on commission. Cases were seen where mothers decided to continue with pregnancy of affected foetus but their judgement been questioned by the healthcare providers(Edwin et al., 2011). Another challenge is the counselling prowess

\section{REFERENCES}

American College of Obstetricians and Gynaecologists. (2008). Ethical issues in genetic testing. ACOG committee opinion, Number 410.

Edwin, A.K., Edwin, F. and Etwire, V. (2011). Controlling sickle cell disease in Ghana - Ethics and options. Pan African Medical Journal, 10:14.

Fadare, J. O. (2009). Some ethical issues in the prenatal diagnosis of sickle cell anaemia. Annals of Ibadan Postgraduate Medicine, 7:2.

Gates, E.A. (1993). Ethical considerations in prenatal diagnosis, In Fetal Medicine required by the healthcare workers. In African context the supply of well-trained and competent genetic counsellors is limited (VanNiekerk, 2014). Myths and beliefs affect the counselling processes as some disorders are belief to be ancestral spirit that descend down the filial generation. Communication and interaction during counselling session is seen poor as local languages are usually used and issues like meaning of words like gene and chromosomes may not be explained and dealt with accordingly (Kromberg et al., 2014).

Ethicists argued the emphasis on genetic testing as regard to informed consent, that many non-genetic tests have consequences that are similar to those of genetic tests. Such consequences include information disclosure, stigmatization and psychological distress (American College of Obstetricians and Gynaecologists, 2008). It is firmly maintained by other ethicists that genetic tests require exceptional consent because they prognosticate future diseases and eventually subject carriers to discernment on many ground and levels; from filial to societal. Testing results might have concerns related to choices regarding current and future health, insurance coverage, career, marriage, or reproductive options (American College of Obstetricians and Gynaecologists, 2008).

\section{CONCLUSION}

Nigerian law has prohibited selective abortion and the big question here is, what is the real objective of prenatal diagnosis? The expectant parents are only in case of affected foetus prepared to raise a child with genetic disorder. This may lead to illegal abortion and may come with its complication since most illegal abortions are carried out by quacks.

Prevention of genetic diseases can be achieved ethically through public education, testing for carriers, and genetic counselling for reproductive choices rather than through PND and selective abortion.

[Special Issue]. Western Journal of Medicine, 159:391-395.

Henn, W. (2000). Consumerism in prenatal diagnosis: a challenge for ethical guidelines. Journal of Medical Ethics, 26:444-446.

Jong, A., Dondorp, W. J., Die-Smulders, C.E.M., Frints, S.G.M. and Wert, G.M.W.R. (2010). Non-invasive prenatal testing: ethical issues explored. European Journal of Human Genetics, 18, 272277. 
Kromberg, J.G.R., Sizer, E. B. and Christianson, A. L. (2013). Genetic services and testing in South Africa. Journal of Community Genetics, 4:413-423.

Maurice, O. I. (2011). Right to life and abortion debate in Nigeria: a case for the legislation of the principle of doubleeffect Nnamdi Azikiwe University journal of international law and jurisprudence, 2.

Satesh, T. and Ahuja, Y.R. (1997). Ethical issues in molecular detection of presymptomaticgenetic disease, prenatal diagnosis and genetic manipulation. Bioethics in India: Proceedings of the International Bioethics Workshop in Madras: Biomanagement of Biogeoresources, 1619, University of Madras.
Van-Niekerk, A. A. (2014). Three ethical issues in the development of public genetic health policies in Africa. Journal of AIDS and Clinical Research, 5:12.

Wertz, D.C., Fletcher, J.C. and Berg, K. (2003). Review of Ethical Issues in Medical Genetics. Report of Consultants to WHO. Geneva: WHO p.102.

World Health Organization. (1998). Proposed international guidelines on ethical issues in medical genetics and genetic services. Report of a WHO meeting on ethical issues in medical genetics, Geneva, 15-16 December, 1997.

World Health Organization. (1999). Ethical practice in laboratory medicine and forensic pathology. WHO regional publications, Eastern Mediterranean Series 20, Alexandria, Egypt. 